\title{
Analysis of Instantaneous and Continuous Migration of Radionuclides from Disposal Facility
}

\author{
Narmine Salah Mahmoud \\ National Center for Nuclear Safety and Radiation Control, Atomic energy Authority Nasr City, Cairo, Egypt \\ E-mail:Mnarmine1@hotmail.com \\ Received April 27, 2011; revised May 30, 2011; accepted June 7, 2011
}

\begin{abstract}
Many disposal sites have been suffered from radionuclide release problems, which lead to land contamination. Various remediation procedures have been developed during the past decade. Selection of remediation techniques is dependant mainly on quantity and quality of radioactive contamination. For that reason, the understanding of the factors that control the degree of contamination of any land should be the start of this problem. The present work aimed to construct the base of a new mandatory chapter in the safety analysis report that discuss and predict quantitively and qualitively the possible release from disposal site. The objective of this chapter is to prevent, restrict, and/or remediate economically the contamination that can be occurred. In the present work, a generic disposal system was evaluated. The radio-elements, which can contaminate the area before their decays, are determined by a screening process. Knowing that the mode of radionuclide migration from a disposal site is one from the important factors that control the contamination problem; migration activity of the selected radionuclides is assessed by considering instantaneous and continuous modes release of radionuclides from the disposal site. Finally, the elementary analysis steps demonstrated in this study will be concluded as the proposed items in the new chapter.
\end{abstract}

Keywords: Disposal, Land Contamination, Remediation, Safety Analysis Report, Safety Assessment Study, Instantaneous and Continuous Flow

\section{Introduction}

Recently disposal site of low and intermediate radioactive waste is represented one of most important radiological installation. Many disposal sites have been suffered from release problems that lead to land contamination. This contamination is resulted from gradual leaching of radionuclides to the surrounding and subsequent migration through environmental media. That release may arise from gradual processes, such as degradation of barriers, and from discrete events that may affect the isolation of the waste. Therefore safety analysis report should be prepared for revision by regulatory committee before the installation of a disposal facility. Safety assessment study of the disposal site is considered one of the most important chapters in this report [1]; safety assessment is the procedure for evaluating performance of disposal system and, as a major objective, its potential radiological impact on human health and the environment [2]. This evaluation shall need to project to the fact that is not practical that remedial action alternative, which include a surface barrier and institutional controls remains in perpetuity [3]. In case of land contamination, various remediation techniques may be applied. However, these techniques are very expansive processes, and in some situation they may increase the pollution problem if improper process is used. Based on this fact, the present work aimed to construct the base of a new mandatory chapter in the safety analysis report discuss and predict quantatively and qualitively the possible release from disposal site to prevent, to restrict, and/or to remediate economically the contamination that have been occurred.

\section{Case Study}

\subsection{Source Term}

The source term considered in this work has been adopted from the report "Near Surface Radioactive Waste Disposal Facilities (NSARS)"; an IAEA CRP project. From NSARS project, twelve radionuclides in 
homogeneous distribution mixture are represented the buried waste in a vault disposal structure. The radionuclides were selected to be common radionuclides with a variety of half-life and distribution coefficient and radiotoxicity as shown in Table 1 [4].

\subsection{Site Characteristics and Hydrological Parameters}

Inshas area is assumed the geological site for disposal system, characteristics and hydrological parameters values of this area are represented by Table 2 . Accordingly, the absolute level of the ground water are undertaken to be in the range from 12.5 to $13 \mathrm{~m}$ above the sea level. The surficial aquifer is the quaternary water bearing formation. It composed of loose sand rounded to subrounded very coarse to fine well sorted, occasionally, with gravel lenses which accelerating the percolation of groundwater to be detected in shallow wells. The thickness of this aquifer area ranges from few meters in the extreme west to about $48 \mathrm{~m}$. It is underlined by thin bed of clay followed by basalt. The permeability coefficients are ranged from $4.9 \times 10^{-3} \mathrm{~cm} / \mathrm{sec}$ to $8.1 \times 10^{-3} \mathrm{~cm} / \mathrm{sec}$, which indicate a low permeable aquifer. The transmissibility of the aquifer ranges from $56.7 \mathrm{~m}^{3} /$ day $/ \mathrm{m}$ to 100 $\mathrm{m}^{3} /$ day/m at the prevailing water temperature [5].

\subsection{Scenario Considered}

The generic scenario is considered the release of radionuclide from the disposal area after the institutional control time of 100 years. The daughters of radionuclide, the effect of chemical reactions, solubility and dilution processes, and transport of radionuclides by colloidal particles are not considered in the present work. Considering four vaults for the burial of radionuclides are installed in the site.

Concerning the analysis of the two modes, two distances 10 and $100 \mathrm{~m}$ are selected to be the checked distance around the disposal site for the calculation of migration rate of radionuclides within the restricted area $(100 \mathrm{~m})$. Restricted area, defined by the National Regulator Commission of United State, means an area, access to which is limited by the licensee for the purpose of protecting individuals against undue risks from exposure to radiation and radioactive materials. Restricted area does not include areas used as residential quarters, but separate rooms in a residential building may be set apart as a restricted area.The selection distance of $10 \mathrm{~m}$ is considered appropriate distance for a beginning of the remediation technique. The second selection is 100 $\mathrm{m}$, which selected to be the extreme contaminated distance that should not crossed (the $100 \mathrm{~m}$ is known as a suitable restricted area around the disposal site).

Based on the scenario of land contamination; 1) for instantaneous flow, an immediately total release of radionuclides from the site will occur after the institutional control of 100 years, 2) a continuous flow of radionuclides release will occur during additional 100 years in case of continuous flow study. The unsaturated zone (vadoze zone) is considered delay time for the radionuclides movement and dispersion in this zone is neglected. Therefore, the evaluation demonstrates the two modes of migration through the saturated zone of the geological

Table 1. Specifications of radionuclides considering in this study.

\begin{tabular}{ccccc}
\hline Radio-nuclide & Half-Life $\mathbf{( y )}$ & Total Inventory $\mathbf{( B q )}$ & Distribution coefficient $\left(\mathbf{c m}^{\mathbf{3}} \mathbf{g}\right)$ [4] & Ingestion dose factor (Sv/Bq) [5] \\
\hline H-3 & $1.24 \mathrm{E}+01$ & $4.00 \mathrm{E}+11$ & $0.00 \mathrm{E}+00$ & $1.70 \mathrm{E}-11$ \\
C-14 & $5.73 \mathrm{E}+03$ & $4.00 \mathrm{E}+10$ & $5.00 \mathrm{E}+00$ & $5.70 \mathrm{E}-10$ \\
Co-60 & $5.30 \mathrm{E}+00$ & $4.00 \mathrm{E}+11$ & $1.50 \mathrm{E}+01$ & $7.30 \mathrm{E}-09$ \\
Ni-59 & $7.50 \mathrm{E}+04$ & $4.00 \mathrm{E}+07$ & $4.00 \mathrm{E}+02$ & $5.70 \mathrm{E}-11$ \\
Ni-63 & $1.00 \mathrm{E}+02$ & $4.00 \mathrm{E}+12$ & $4.00 \mathrm{E}+02$ & $1.50 \mathrm{E}-10$ \\
Se-79 & $6.50 \mathrm{E}+04$ & $4.00 \mathrm{E}+07$ & $1.50 \mathrm{E}+02$ & $2.35 \mathrm{E}-09$ \\
Sr-90 & $2.88 \mathrm{E}+01$ & $4.00 \mathrm{E}+12$ & $1.50 \mathrm{E}+01$ & $3.60 \mathrm{E}-08$ \\
Tc-99 & $2.13 \mathrm{E}+05$ & $4.00 \mathrm{E}+07$ & $1.00 \mathrm{E}-01$ & $3.95 \mathrm{E}-10$ \\
Ru-106 & $1.08 \mathrm{E}+00$ & $4.00 \mathrm{E}+10$ & $5.00 \mathrm{E}+01$ & $7.40 \mathrm{E}-09$ \\
Cs-134 & $2.06 \mathrm{E}+00$ & $4.00 \mathrm{E}+07$ & $3.00 \mathrm{E}+02$ & $2.00 \mathrm{E}-08$ \\
Cs-137 & $3.02 \mathrm{E}+01$ & $4.00 \mathrm{E}+12$ & $3.00 \mathrm{E}+02$ & $2.00 \mathrm{E}-08$ \\
Th-230 & $7.70 \mathrm{E}+04$ & $4.00 \mathrm{E}+09$ & $3.00 \mathrm{E}+03$ & $1.50 \mathrm{E}-07$ \\
\hline
\end{tabular}


Table 2. The hydrological parameters of the site.

\begin{tabular}{cc}
\hline Factor & Value [5] \\
\hline Vertical distance of unsaturated zon $(x)$ & $13 \mathrm{~m}$ \\
Velocity of flow in the unsaturated zone $(v)$ & $0.0039 \mathrm{~m} / \mathrm{s}$ \\
Effective Porosity of the sand soil $(\theta)$ & $25 \%$ \\
Density of the sand soil $(\rho)$ & $2.6 \mathrm{~g} / \mathrm{cm}^{3(3)}$ \\
Seepage velocity in the aquifer & $0.04 \mathrm{~m} / \mathrm{d}$ \\
Dispersion coefficient in x direction $D_{x}$ in the aquifer & $268.3 \mathrm{~m} /$ year \\
Dispersion coefficient in y direction $D_{y}$ & $134.1 \mathrm{~m}^{2} /$ year \\
\hline
\end{tabular}

site (aquifer).

\section{Theoretical Release Models}

\subsection{Screening Model}

The radionuclides that can contribute in the pollution of land, according to its half-life, radio-activity and/or retardation through the soil, are calculated by conservative screening model based on $1 \mathrm{mSv} / \mathrm{y}$ as a limit value for personal exposure dose [6]. The screening model is calculated based on the ingestion dose as follows:

$$
I=I_{o} \cdot \mathrm{e}^{-\lambda T} * \operatorname{Ding}
$$

where:

$I$ is the activity of radionuclides calculated after the travel time of the unsaturated zone $[B q], I_{o}$ is the initial activity of radionuclides in $\mathrm{Bq}$, Ding is the ingestion dose factor of radionuclide $[S v / B q]$

$$
\lambda=\ln 2 / \mathrm{t}
$$

where:

$\lambda$ is the decay constant, dimensionless, $t$ is the radionuclide half-life $[T]$

$$
T=T_{1}+T_{2}
$$

$T 1$ is the institutional control period $[T], T_{2}$ is the travel time of unsaturated $[T]$

$$
\begin{gathered}
T=\frac{X_{u} R_{d}}{U_{u}} \\
U_{u}=\frac{v_{u}}{\theta} \\
R_{d}=1+\rho \frac{K_{d}}{\theta}
\end{gathered}
$$

where:

$X_{u}$ is the thickness of the unsaturated and saturated zone $[L], U_{u}$ is the seepage velocity of radionuclides in unsaturated and saturated zone $[L / T], v_{u}$ and $v_{s}$ are the velocity of radionuclide in unsaturated and saturated zone $[L / T], \theta$ is the effective porosity of the zone.

$R_{d}$ is the retardation coefficient of radionuclide within the soil, dimensionless.

(The soil type in the unsaturated zone and the saturated zone is of sand type, so the retardation is equal for both zones, the same for the density and porosity)

$\rho$ is the density of the soil in $\left[M / L^{3}, K_{d}\right.$ is the distribution coefficient of the radionuclide in $\left[L^{3} / M\right]$.

\subsection{Modes of Release}

The flow in both cases instantaneous and continuous cases is assessed as linear source in horizontal direction and analyzed using the equations:

\subsubsection{Instantaneous Release}

According to the scenario proposed, serious event was assumed attack the disposal structure leads to rapid release flow of all buried radionuclides to the surrounding area. In this case, the equation used to analyze the flow is as follows [7]:

$$
\begin{gathered}
C_{i}=\frac{C_{o}}{n_{e} \cdot R_{d}} X Y Z \\
X=\frac{1}{\sqrt{4 \pi D_{x} t / R_{d}}} \exp \left[-\frac{\left(x-U t / R_{d}\right)^{2}}{4 D_{x} t / R_{d}}\right] \\
Y=\frac{1}{\sqrt{4 \pi D_{y} t / R_{d}}} \exp \left[-\frac{y^{2}}{4 D_{y} t / R_{d}}\right] \\
Z=\frac{1}{b}
\end{gathered}
$$

where:

$C_{I}$ is the activity of radionuclide at $x$ and $t\left[B q / L^{3}\right], C_{o}$ is the initial concentration $\left[\mathrm{Bq} / \mathrm{l}^{3}\right]$.

$n_{e}$ is the effective porosity dimensionless, $D_{x}$ is the dispersion coefficient in the $x$ direction $\left[L^{2} / T\right], D_{y}$ is the dispersion coefficient in the $y$ direction $\left[L^{2} / T\right], x$ is the distance in $x$ direction $[L], y$ is the distance in $y$ direction $[L], b$ is the length of the vertical line $[L]$.

$t$ is the time considered during the calculation $[T]$.

\subsubsection{Continuous Release}

A small rupture in the base of the disposal structure is assumed resulting, which can be formed by ageing effect of concrete material or from biological attack. That offers a continuous small release flow of radionuclide to the surrounding area to take place. The movement of the flow can be treated in this case using the following equation [8]:

$$
C_{i}=\left(C_{o} / 4\right) X Y
$$




$$
\begin{gathered}
X=\operatorname{erfc}\left[(x-U t) / 2\left(D_{x} t\right)^{1 / 2}\right] \\
Y=\operatorname{erf}\left[(y+z / 2) / 2\left(D_{y} x / V\right)^{1 / 2}\right] \\
-\operatorname{erf}\left[(y-z / 2) / 2\left(D_{y} x / V\right)^{1 / 2}\right]
\end{gathered}
$$

where:

$y$ is the source boundary in the $y$ direction $[L], z$ is the line source length $[L]$.

The other parameters were defined before.

The equation was modified to take into account the effect of the retardation coefficient of radionuclides. The modification in the equation was applied on the seepage velocity of the contaminant flow in the aquifer [9]. The $X$ part in the equation is modified as follows:

$$
X=\operatorname{erfc}\left[\left(x-U t / R_{d}\right) / 2\left(D_{x} t\right)^{1 / 2}\right]
$$

The decay of radionuclides is considered in the calculation in both cases by multiply the Equations (3) and (4) by the function $\mathrm{e}^{-\lambda T}$.

\section{Results and Discussions}

Table 3 shows the radionuclides resulted from the screening calculation based on Equation (1), taken in consideration that the start of evaluation is after the end of 100 years institutional control period. All radionuclides having absorbed dose lower than $1 \mathrm{mSv} / \mathrm{y}$ is excluded from the evaluation.

\subsection{Instantaneous Release Mode}

Figures 1(a) and (b) demonstrates the migration amount of radionuclides in the saturated zone reaches the distance 10 and 100 consecutively from the disposal site. According to the behavior of radionuclide element with the soil, each element reaches the distance considered at different time and different concentration. Tc-99, in Figure 1(a), is the first radionuclide appears at $10 \mathrm{~m}$ before $\mathrm{C}-14$ and the second radionuclide appears at 100 $\mathrm{m}$ in Figure 1(b) followed by C-14. That can be explained by the bulk activity of Tc-99, which moves without any retention or interaction with soil. In case of Sr-90; it shows the highest amount of activity followed by $\mathrm{C}-14$ and Ni-63. Regarding Ni-59, Ni-63, Se-79, and Cs-137 appear very slowly despite their relatively high activity. That can be explained by the retention of these radionuclides on the soil. No appearance is calculated for Th-230 during the 100 years after the institutional control of disposal site. That can be referring to its retardation on soil.

Two radionuclides are selected for more understand-
Table 3. Radionuclides obtained after the screening calculations.

\begin{tabular}{ccc}
\hline Radionuclide & Half-life (yr) & $\begin{array}{c}\text { Activity (Bq) } \\
\text { In the four vaults }\end{array}$ \\
\hline C-14 & $5.73 \mathrm{E}+03$ & $3.95 \mathrm{E}+10$ \\
Ni-59 & $7.50 \mathrm{E}+04$ & $4.00 \mathrm{E}+07$ \\
Ni-63 & $1.00 \mathrm{E}+02$ & $1.99 \mathrm{E}+12$ \\
Se-79 & $6.50 \mathrm{E}+04$ & $4.00 \mathrm{E}+07$ \\
Sr-90 & $2.88 \mathrm{E}+01$ & $3.60 \mathrm{E}+11$ \\
Tc-99 & $2.13 \mathrm{E}+05$ & $4.00 \mathrm{E}+07$ \\
Cs-137 & $3.02 \mathrm{E}+01$ & $3.99 \mathrm{E}+11$ \\
Th-230 & $7.70 \mathrm{E}+04$ & $4.00 \mathrm{E}+09$ \\
\hline
\end{tabular}

ing the migration behavior of radionuclides within the soil; C14 and Cs-137 as shown in Figure 2.

This figure describes the relation between the activity and the time on 10 and $100 \mathrm{~m}$ for the radio-element $\mathrm{C}-14$ and Cs-137. The relation is represented in the form of area scale. In chart a, C-14 takes a relatively short time of 1 year after the release to contaminate the $10 \mathrm{~m}$ from the disposal unit and reach maximum concentration after 3 years. C-14 according to his half-life has not loose activity during the total duration of 200 years starting from disposal time to the end of the study (the start of the simulation is after the 100 years institutional control period and 100 years for the study). Its maximum concentration is $0.0241 \%$ and $0.0238 \%$ from initial activity on 10 and $100 \mathrm{~m}$ respectively. This reflects its capability to cross the $100 \mathrm{~m}$ without loosing a real activity and pollute longer movement of Cs-137 on $10 \mathrm{~m}$ and $100 \mathrm{~m}$, the Cs-137 appears at 8.5 years (approximate) and reaches its maximum concentration in 60 years on $10 \mathrm{~m}$. Its maximum concentration is $1 \mathrm{E}-06 \%$ from initial activity. In contrary of C-14, Cs-137 looses activity during its migration by the effect first by time, and by sorption in soil.

The (c) chart in Figure 2 compares the two radionuclides on $10 \mathrm{~m}$. C-14 appears before Cs-137 and reaches its maximum concentration and its activity decreases to 5.58E06 Bq with the first activity calculated for Cs- 137 after 8.5 years. The decrease of activity is represented the start of migrated flow of radionuclide to the adjacent distance as shown in chart $d$ as dark area. This early appearance is expected and can be explained by the lower retardation factor of C-14 than Cs-137.

Figure 3 describes a deep analysis of the instantaneous movement of radionuclides crosses different adjacent distances and the amount of activity accumulated on each distance within the time. The charts (a) and (b) represent the movement of $\mathrm{C}-14$ and Cs-137 respectively. The 


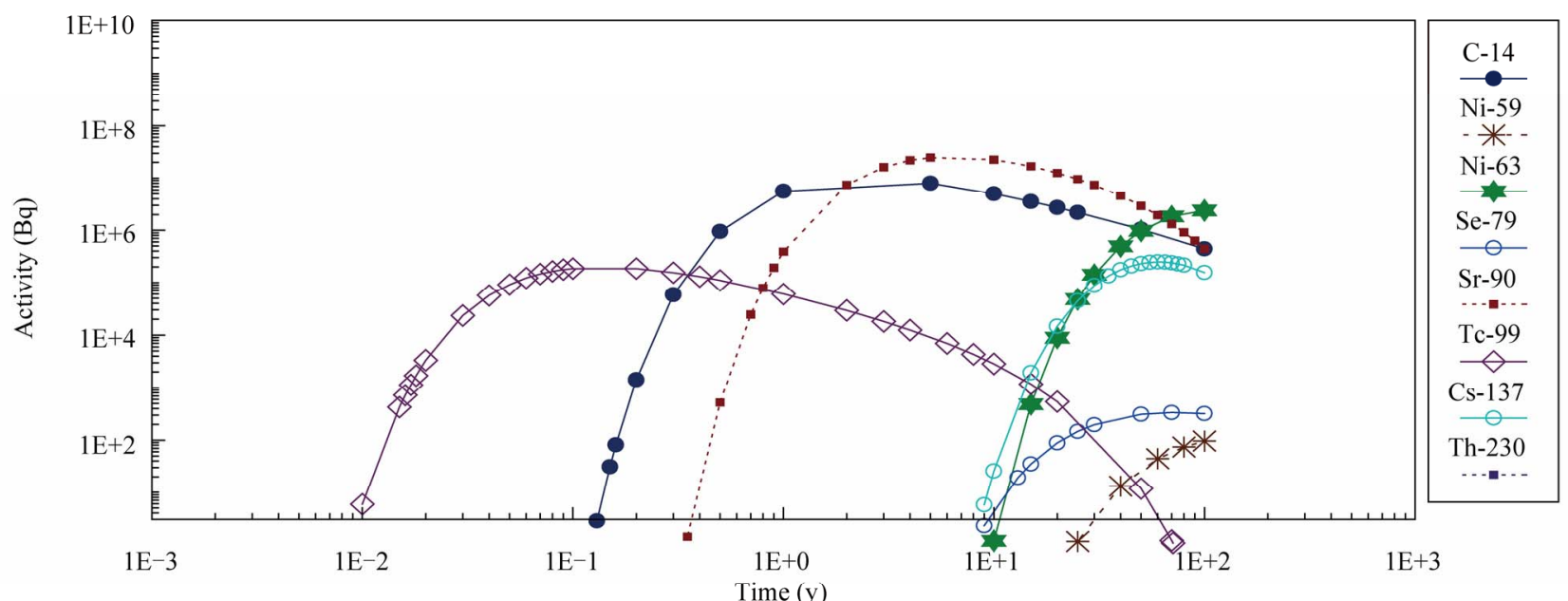

(a)

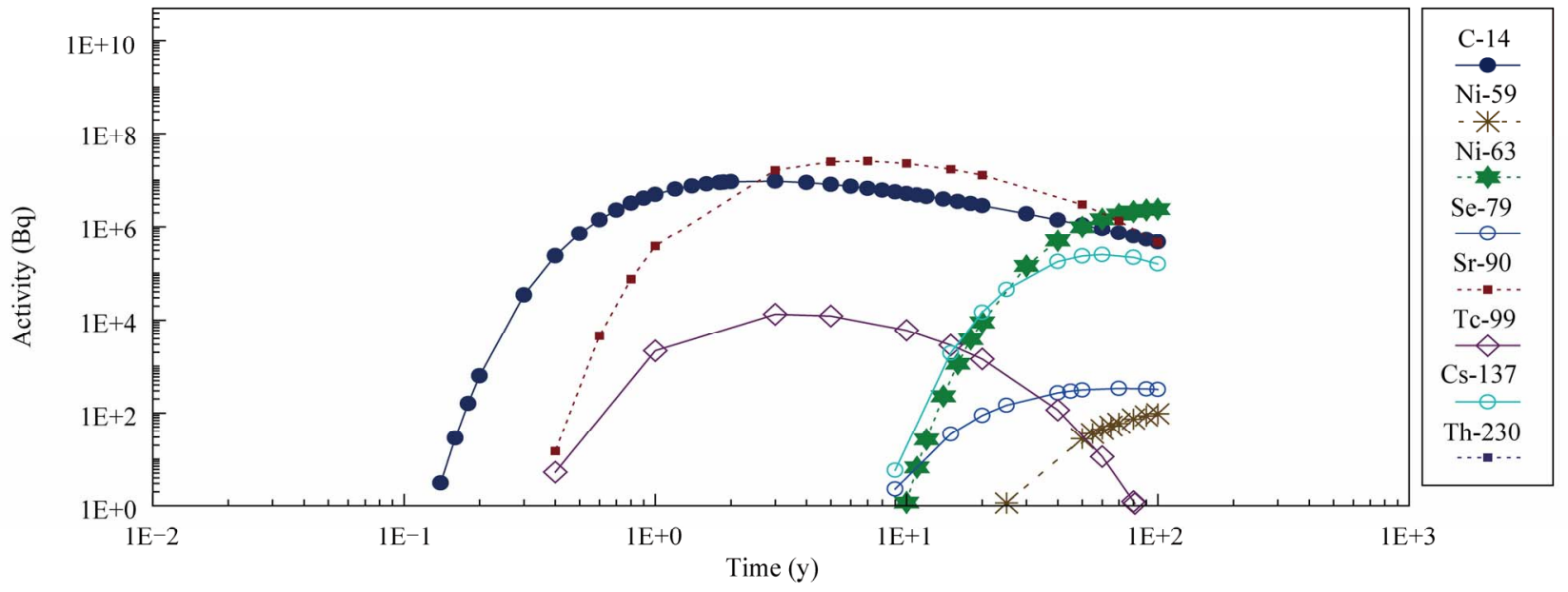

(b)

Figure 1. Instantaneous release of radionuclides during 100 years after the end of institutional control period within the restricted zone, (a) at $10 \mathrm{~m}$ from the disposal site; (b) at $100 \mathrm{~m}$ from the disposal site.

movement of C-14, with little tendency to dispose on the soil, behaves relatively in rapid motion. That is indicated by the complete similar time-activity curve on the adjacent distance (dark area). That is not the case for Cs-137, which takes higher time to move and can not complete its migration time-activity curve on the adjacent distance. The area under each curve represents the contaminated area by the radionuclide.

The inside small charts in charts (a) and (b) show this relation on the same different adjacent distances in area form. These charts indicate the sequence of movement with the time. The accumulation of C-14 activity on each soil layer is not similar as in case of Cs-137 as represented in chart $\mathrm{c}$ and $\mathrm{d}$ respectively. The accumulated quantity on each distance has a sharp pyramided form with a maximum value which is not the case of Cs- 137 . The activity of Cs-137 migrated takes the shape of smooth large wave. Again, the negative activity values in the dark area in those charts reflect the migrated activities to next soil layer.

\subsection{Continuous Release Mode}

The study assumes continuous release of $0.01 \%$ of the total activity from the disposal site to the surrounding. That means the flow of release come to end after 100 years from the beginning of the study as it is noted before. Within the same conditions of time and distance of instantaneous release from the disposal site, as in case of instantaneous release on $100 \mathrm{~m}, \mathrm{C}-14$ is the beginner to appear on $10 \mathrm{~m}$ in continuous migration followed by Sr-90 as shown in Figure 4.

However on 50, only the two radionuclides C-14 and Sr-90 keep their ranks. On $100 \mathrm{~m}, \mathrm{C}-14$ is the only nuclide can be detected. In contrary of C-14, Cs-137 looses activity during its migration by the effect first by time, 

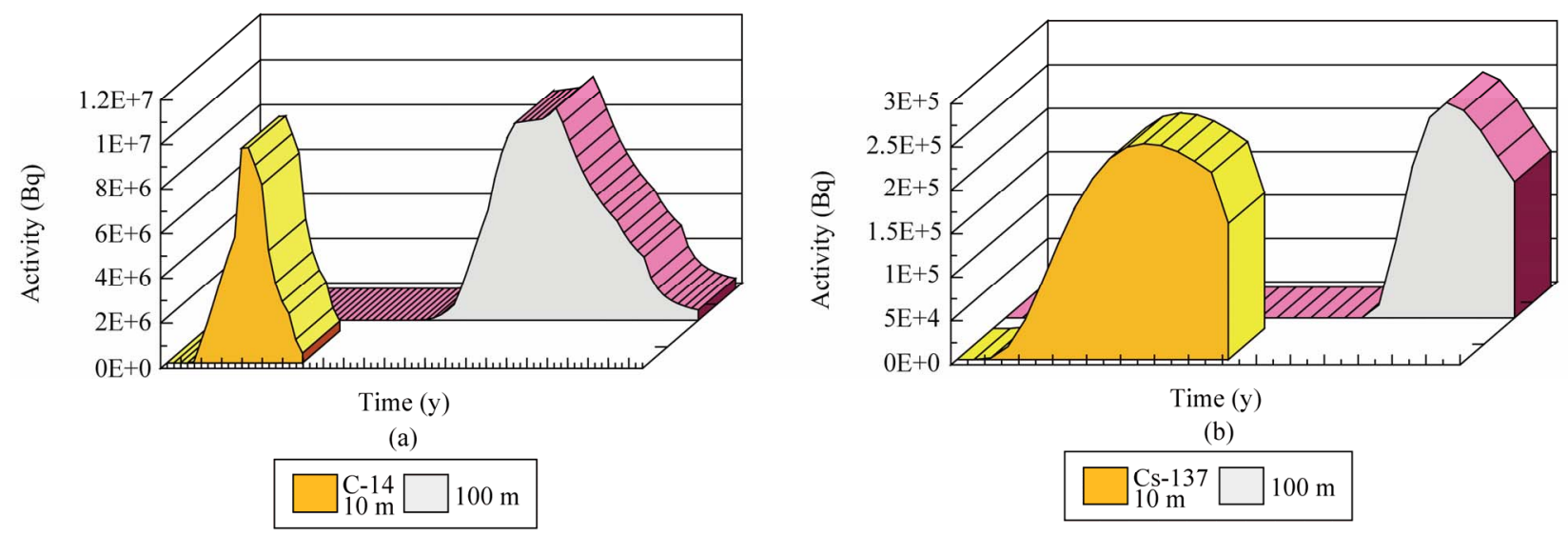

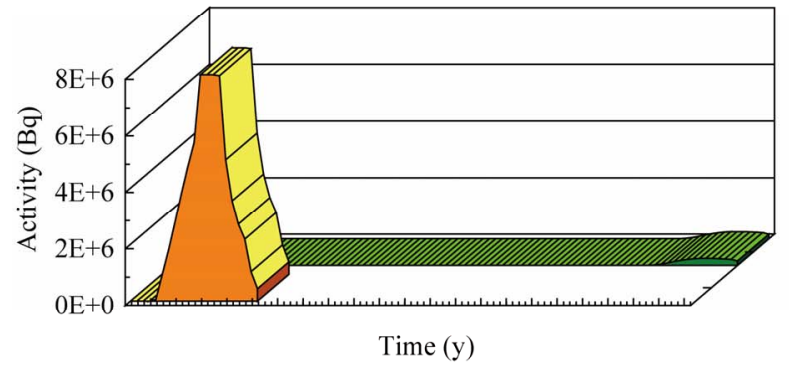

(c)
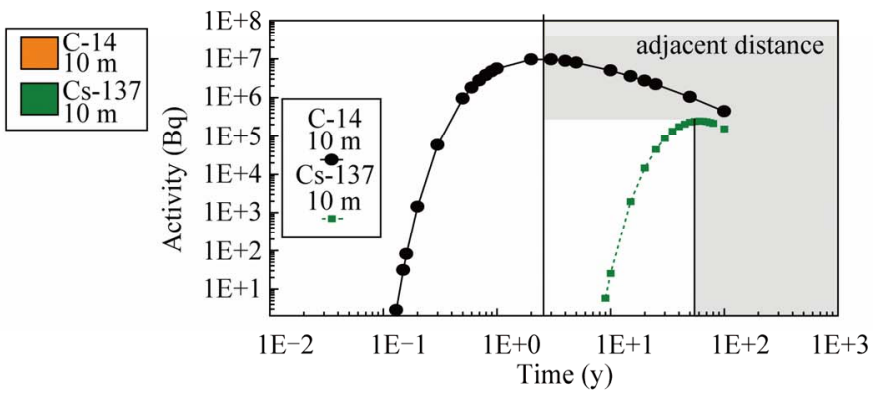

(d)

Figure 2. Instantaneous release time taken by radionuclide migrate from the disposal site within the restricted area.
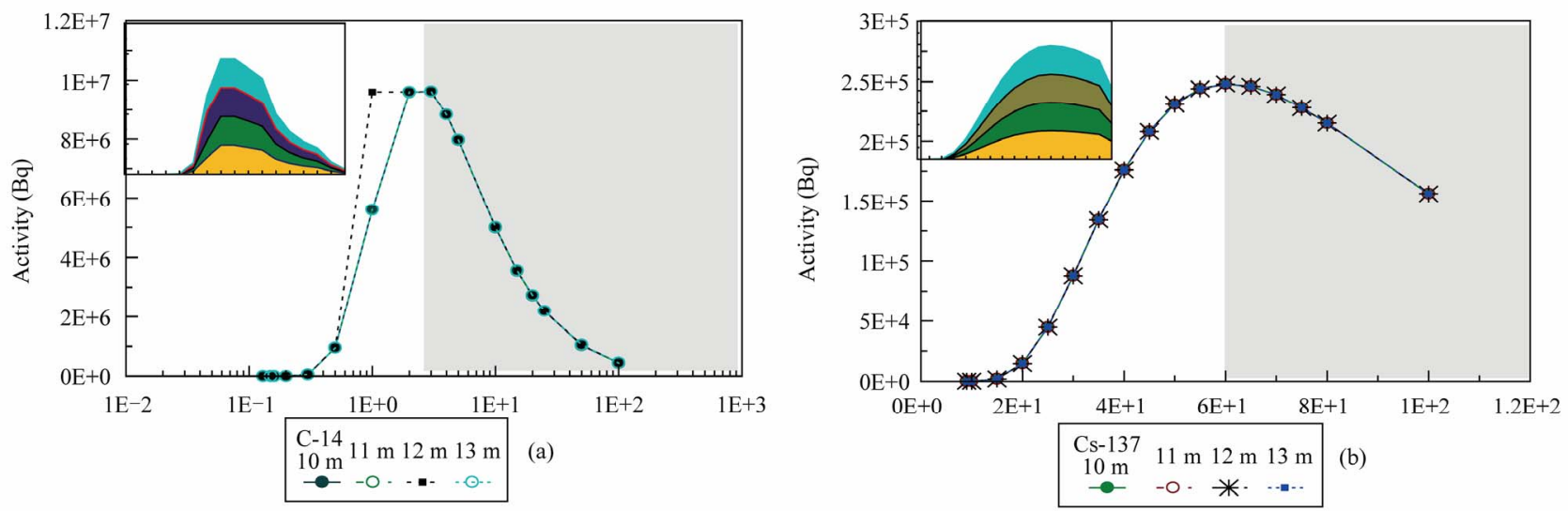

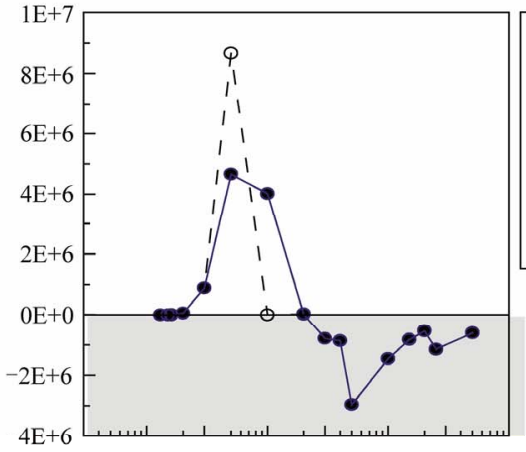

$3 \mathrm{E}^{-2} \quad 1 \mathrm{E}-13 \mathrm{E}-1 \quad 1 \mathrm{E}+0 \quad 3 \mathrm{E}+0 \quad 1 \mathrm{E}+1 \quad 3 \mathrm{E}+1 \quad 1 \mathrm{E}+2$ Time (y)

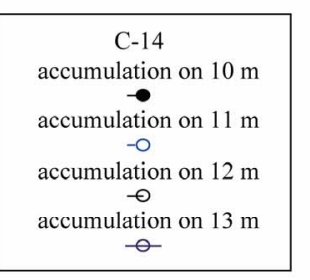

(c)

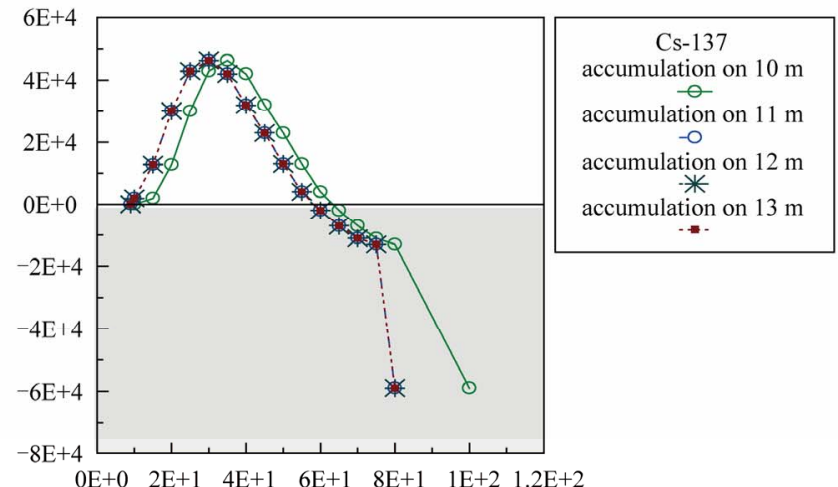

(d)

Figure 3. Analysis of the instantaneous movement on different adjacent distances. 


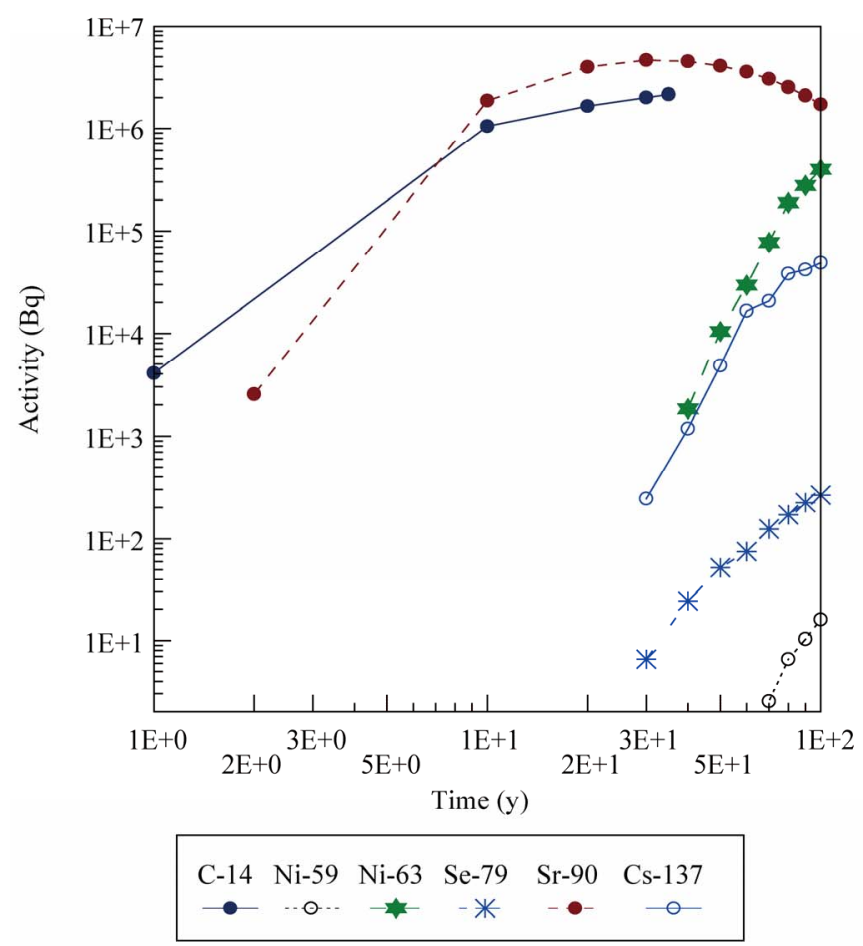

(a)

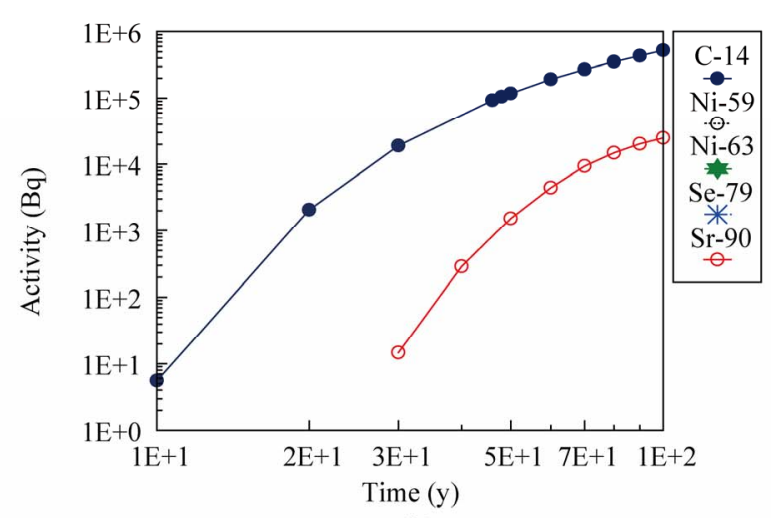

(b)

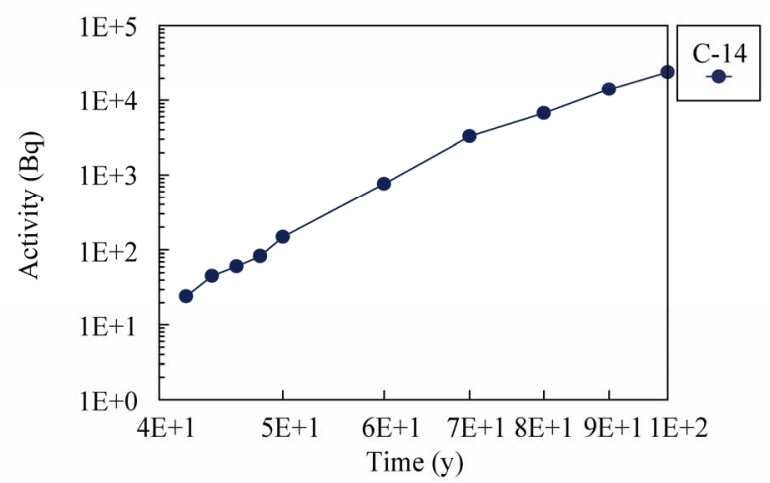

(c)

Figure 4. Release behavior of radinuclide in the continuous mode in the restricted area of the disposal site during the continuous migration of radionuclides (100 years), (a) On 10 m; (b) On 50 m; (b) On 100 m.

and by sorption in soil. Chart (c) and (d) respectively. The accumulated quantity on each distance has a sharp pyramided form with a maximum value which is not the case of.

Again, the radionuclides C-14 and Cs-137 are selected for more analyses and understand the continuous mode. Figure 5 shows the continuous migration of each radionuclide crosses different adjacent distances and the amount of activity remains accumulated on each distance. For C-14, in chart (a), the activity appears increasing layer to layer. The continuous flow is can be considered as multi-consecutive instantaneous flows with constant low concentration or activity of radionuclides. According to the relatively high motion of C-14, the multi-consecutive instantaneous flow appears on the adjacent soil layers very quickly. Each flow migrates to a layer before the leaving of the present flow and without loosing significant amount of activity. The addition of more than one instantaneous flow on the same layers shows a gradually increasing of the flow. Th-230 has no appearance as in case of the instantaneous flow based on its long half-life and distribution coefficient. This is not the case for Tc-99, which considers to be migrated in a short time.

In chart (b) the situation is opposite; the activity of
Cs-137 flow appears decreasing from layer to layer. However this isn't the real case. Owing to the fact that the Cs-137 has a relatively high distribution coefficient in soil (high retardation), each instantaneous flow moves very slowly from layer to the adjacent layer loosing activity on each layer and before the followed flow reach the same layer. The small chart in chart (a) and (b) shows same relation of time-activity in area form for cases of C-14 and Cs-137, no complete curve is presented during the 100 years (no maximum values for radionuclides are presented during this time).

In chart (c) the accumulation of C-14 on each layer is apparently. Each instantaneous flow reaches an occupied layer before the escape of the present flow. This indicates by the gradual increasing of each curve simulate the activity on each layer. However, each curve decreasing with time prove the apparently accumulation and the escape of each flow to the adjacent distance. In chart (d) accumulation of Cs-137, which decreases may prove that charts (b) and (d) describes only one instantaneous flow. On each layer this flow of Cs-137 loose activity and decreasing from layer to layer. The increasing of each curve shows the accumulation of activity on each layer is reflecting the real situation of Cs-137 flow. 

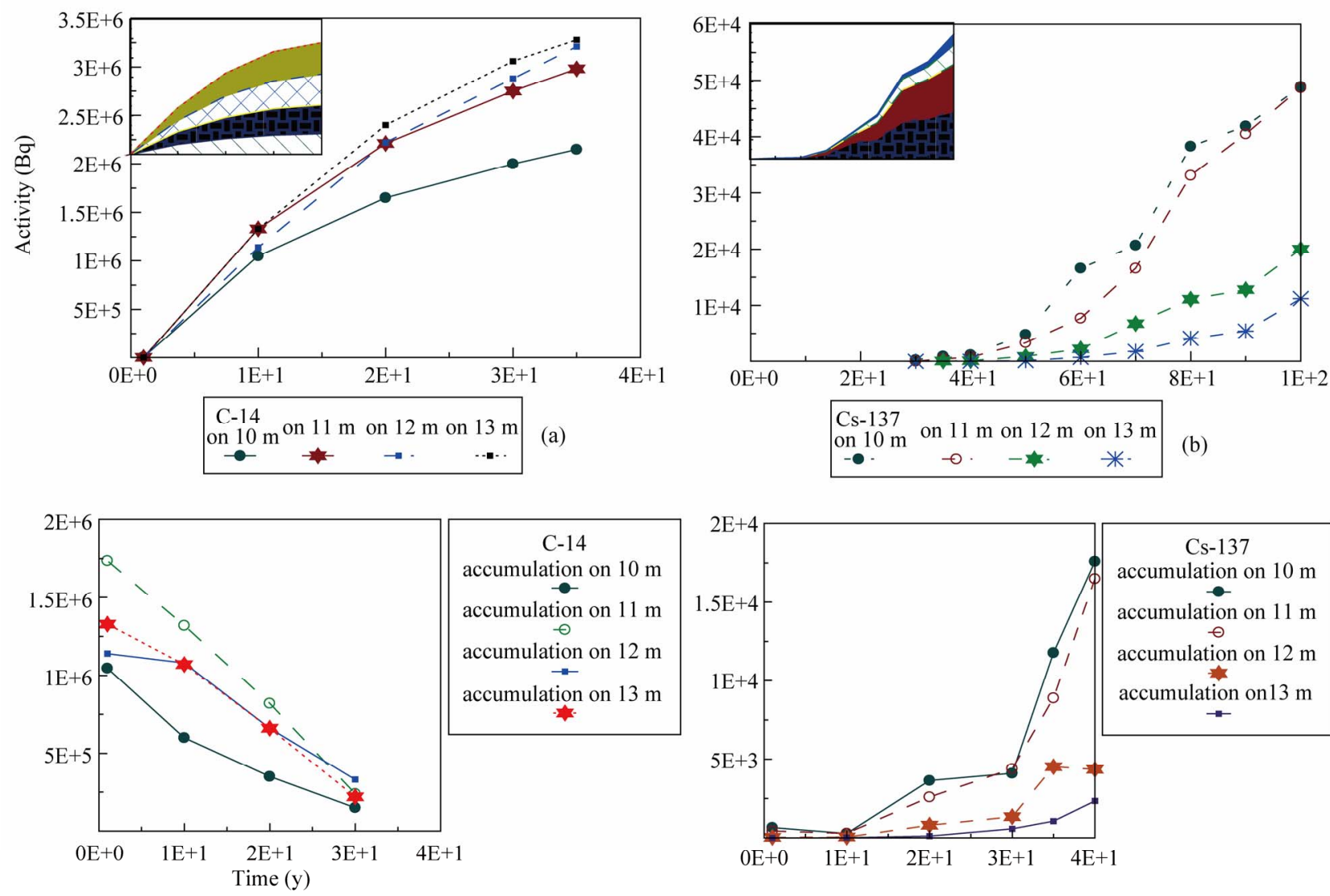

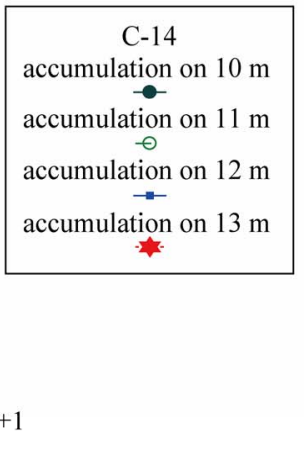

(c)

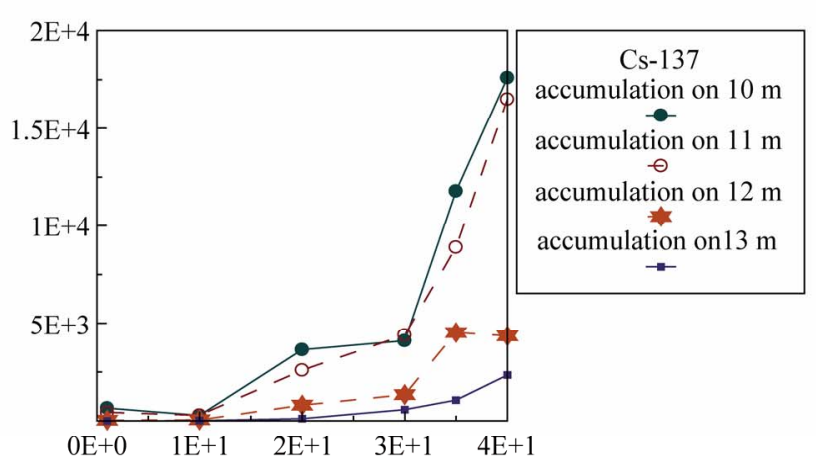

(d)

Figure 5. Analysis of the continuous mode of two different element-radionuclides.

\subsection{Comparison of the Modes Instantaneous and Continuous Flow}

Table 4 listed the appearance rank of radionuclides in both case instantaneous and continuous modes and compares these results with the rank obtained before by the analysis of different parameters. Some radionuclides have kept, in most rank, their position such as; Sr-90, C-14 and Tc-99. Meanwhile, no definitive parameter can be used as indicator for the movement of different radionuclides.

Table 5 listed the different maximum activity values obtained in both cases instantaneous and continuous and their time of appearance. In Both cases, Sr-90 reach the maximum values of activity migrated nearly within same values. Except on $100 \mathrm{~m}$ in the continuous mode, no appearance is calculated for Sr-90. In case of instantaneous mode on 10 and $100 \mathrm{~m}$, the maximum activity calculated is occurred for all radionuclides around the same time expect for Tc-99. Tc-99 is detected as the first radionuclide migrated in the surrounding and this can be the situation in case on the $100 \mathrm{~m}$ in continuous mode.

Table 6 listed the absorbed dose of maximum activity values obtained from the radionuclides to consider conservatively the contamination of the area, which can be occurred. C-14, Sr-90, Cs-137 are showed real threat in most cases. However it should be noted that these values are case specific according to; geological site character-

Table 4. Appearance of Radionuclides obtained from each mode of release.

\begin{tabular}{cccc}
\hline \multicolumn{2}{c}{ Instantaneous } & \multicolumn{2}{c}{ Continuous } \\
\hline $\mathbf{1 0} \mathbf{m}$ & $\mathbf{1 0 0} \mathbf{m}$ & $\mathbf{1 0 ~} \mathbf{~}$ & $\mathbf{1 0 0} \mathbf{~}$ \\
\hline Tc-99 & C-14 & Tc-99 & Tc-99 \\
C-14 & Tc-99 & C-14 & C-14 \\
Sr-90 & Sr-90 & Sr-90 & \\
Se-79 & Se-79 & Se-79 & \\
Cs-137 & Cs-137 & Ni-63 & \\
Ni-63 & Ni-63 & Cs-137 & \\
Ni-59 & Ni-59 & Ni-59 & \\
Th-230 & Th-230 & Th-230 & \\
\hline
\end{tabular}


Table 5. Comparison of the maximum activity and their time of appearance on $10 \mathrm{~m}$ and $100 \mathrm{~m}$ during 100 years.

\begin{tabular}{|c|c|c|c|c|c|c|c|}
\hline \multirow[t]{2}{*}{ Radio-nuclide } & \multirow[t]{2}{*}{$\begin{array}{l}\text { Initial Activity } \\
\text { (Bq) }\end{array}$} & \multicolumn{3}{|c|}{$\begin{array}{c}\text { Maximum Activity } \\
\text { at } \mathbf{1 0} \mathrm{m} \text { in Instantaneous Mode }\end{array}$} & \multicolumn{3}{|c|}{$\begin{array}{c}\text { Maximum Activity } \\
\text { at } \mathbf{1 0} \mathrm{m} \text { in Continuous Mode }\end{array}$} \\
\hline & & Quantity (Bq & n initial activity & Time (y) & Quantity (Bq) & nitial activity & Time (y) \\
\hline C-14 & $3.95 \mathrm{E}+10$ & $7.97 \mathrm{E}+06$ & $2.02 \mathrm{E}-02$ & 5 & $2.00 \mathrm{E}+06$ & $5.06 \mathrm{E}-03$ & 30 \\
\hline Ni-59 & $4.00 \mathrm{E}+07$ & $9.59 \mathrm{E}+01$ & $2.40 \mathrm{E}-04$ & 100 & $1.59 \mathrm{E}+01$ & $3.98 \mathrm{E}-05$ & 100 \\
\hline Ni-63 & $1.99 \mathrm{E}+12$ & $2.39 \mathrm{E}+06$ & $1.20 \mathrm{E}-04$ & 100 & $3.96 \mathrm{E}+05$ & $1.99 \mathrm{E}-05$ & 100 \\
\hline Se-79 & $4.00 \mathrm{E}+07$ & $3.36 \mathrm{E}+02$ & $8.40 \mathrm{E}-04$ & 70 & $2.64 \mathrm{E}+02$ & $6.60 \mathrm{E}-04$ & 100 \\
\hline Sr-90 & $3.60 \mathrm{E}+11$ & $2.47 \mathrm{E}+07$ & $6.86 \mathrm{E}-03$ & 5 & $4.63 E+06$ & $1.29 \mathrm{E}-03$ & 30 \\
\hline Tc-99 & $4.00 \mathrm{E}+07$ & $1.86 \mathrm{E}+05$ & $4.65 \mathrm{E}-01$ & 0.1 & $1.96 \mathrm{E}+03$ & $4.90 \mathrm{E}-03$ & 1 \\
\hline Cs-137 & $3.99 \mathrm{E}+11$ & $2.48 \mathrm{E}+05$ & $6.22 \mathrm{E}-05$ & 60 & $4.89 \mathrm{E}+04$ & $1.23 \mathrm{E}-05$ & 100 \\
\hline Th-230 & $4.00 \mathrm{E}+09$ & - & - & - & - & - & $-\mathrm{s}$ \\
\hline \multirow[t]{2}{*}{$\begin{array}{l}\text { Radio- } \\
\text { nuclide }\end{array}$} & $\begin{array}{l}\text { Initial Activity } \\
\text { (Bq) }\end{array}$ & \multicolumn{3}{|c|}{$\begin{array}{c}\text { Maximum Activity } \\
\text { at } 100 \mathrm{~m} \text { in Instantaneous Mode }\end{array}$} & \multicolumn{3}{|c|}{$\begin{array}{c}\text { Maximum Activity } \\
\text { at } 100 \mathrm{~m} \text { in Continuous Mode }\end{array}$} \\
\hline & & Quantity (Bq & n initial activity & Time (y) & Quantity (Bq) & nitial activity & Time (y) \\
\hline C-14 & $3.95 \mathrm{E}+10$ & $9.51 \mathrm{E}+06$ & $2.41 \mathrm{E}-02$ & 3 & $2.4 \mathrm{E}+04$ & $6.13 \mathrm{E}-05$ & 100 \\
\hline Ni-59 & $4.00 \mathrm{E}+07$ & $9.60 \mathrm{E}+01$ & $2.40 \mathrm{E}-04$ & 100 & - & - & - \\
\hline Ni-63 & $1.99 \mathrm{E}+12$ & $2.39 \mathrm{E}+06$ & $1.20 \mathrm{E}-04$ & 100 & - & - & - \\
\hline Se-79 & $4.00 \mathrm{E}+07$ & $3.36 \mathrm{E}+02$ & $8.40 \mathrm{E}-04$ & 70 & - & - & - \\
\hline Sr-90 & $3.60 \mathrm{E}+11$ & $2.56 \mathrm{E}+07$ & $7.11 \mathrm{E}-03$ & 7 & - & - & - \\
\hline Tc-99 & $4.00 \mathrm{E}+07$ & $1.34 \mathrm{E}+04$ & $3.35 \mathrm{E}-02$ & 3 & - & - & - \\
\hline Cs-137 & $3.99 \mathrm{E}+11$ & $2.48 \mathrm{E}+05$ & $6.22 \mathrm{E}-05$ & 60 & - & - & - \\
\hline Th-230 & $4.00 \mathrm{E}+09$ & - & - & - & - & - & - \\
\hline
\end{tabular}

ristics, type and quantity of waste buried, and time of radionuclide release. Additionally, it is important to remember that the present study has neglected the effect of dilution and chemical processes, which is present in real situations.

The absorbed doses calculated and presented in Table 6 for some cases are not expected. For example Tc-99 in spite of quickly migration, its dose calculated does not generate real pollution derived from the ingestion dose conversion factor. The same situation is shown in all case for Ni-59, Ni-63, and Se-79.

Figure 6 evaluates the difference in movement and quantity of activity migration in both cases instantaneous and continuous modes. In case of C-14, the movement in continuous mode shows slow movement than in instanttaneous mode. The quantity of activities is higher in case of instantaneous case within limited distance. For Cs-137, the activity in the flow, which moves from layer to layer, is higher in case of instantaneous mode. On the other hand, the accumulation of activity on any layer can be higher than the flow migrated on it. This can be ex- plained by the property of continuous mode to offer multi-contact time of the waste multi-instantaneous flows in continuous mode with each soil increment. On other words, instantaneous release crossed each increment of soil once time; that increment does not the enough time to retain radionuclides.

\section{Conclusions}

The objective of the study is not only to evaluate the two modes and compare, but to estimate possible pollution, which can occur for a disposal site. This estimation gives an early overview for keeping the performance of disposal sites until the buried radionuclide reach certain decay, which does not leads to any pollution. Additionally, the study tries to establish basis for the preparation of remediation actions in case of any release. The present study concludes the following:

- The safety analysis for a disposal site should contain a separate chapter study the possible land pollution and the suitable remediation techniques [10-17]. 
Table 6. Calculated absorbed dose in both cases instantaneous and continuous modes.

\begin{tabular}{|c|c|c|c|c|c|}
\hline \multirow{2}{*}{ Radionuclide } & \multirow{2}{*}{$\begin{array}{l}\text { Ingestion dose conversion factor } \\
\text { (Sv/Bq) }\end{array}$} & \multicolumn{2}{|c|}{$\begin{array}{l}\text { Dose from Instantaneous mode } \\
(\mathrm{mSv} / \mathrm{y})\end{array}$} & \multicolumn{2}{|c|}{$\begin{array}{l}\text { Dose from Continuous mode } \\
(\mathrm{mSv} / \mathrm{y})\end{array}$} \\
\hline & & $10 \mathrm{~m}$ & $100 \mathrm{~m}$ & $10 \mathrm{~m}$ & $100 \mathrm{~m}$ \\
\hline C-14 & $5.7 \mathrm{E}-10$ & $4.54 \mathrm{E}+00$ & $5.42 \mathrm{E}+00$ & $1.14 \mathrm{E}+00$ & $1.32 \mathrm{E}-02$ \\
\hline $\mathrm{Ni}-59$ & $5.7 \mathrm{E}-11$ & $5.47 \mathrm{E}-06$ & $5.47 \mathrm{E}-06$ & $9.06 \mathrm{E}-07$ & \\
\hline $\mathrm{Ni}-63$ & $1.5 \mathrm{E}-10$ & $3.59 \mathrm{E}-01$ & $3.59 \mathrm{E}-01$ & $5.94 \mathrm{E}-02$ & \\
\hline Se-79 & $2.35 \mathrm{E}-09$ & $7.90 \mathrm{E}-04$ & $7.90 \mathrm{E}-04$ & $6.20 \mathrm{E}-04$ & \\
\hline Sr-90 & $3.6 \mathrm{E}-08$ & $8.89 E+02$ & $9.22 E+02$ & $1.67 E+02$ & \\
\hline Tc-99 & $3.95 \mathrm{E}-10$ & $7.35 \mathrm{E}-02$ & $5.29 \mathrm{E}-03$ & $7.74 \mathrm{E}-04$ & \\
\hline Cs-137 & $2 \mathrm{E}-08$ & $4.96 \mathrm{E}+00$ & $4.96 \mathrm{E}+00$ & $9.78 \mathrm{E}-01$ & \\
\hline Th-230 & $1.5 \mathrm{E}-07$ & - & - & - & - \\
\hline
\end{tabular}
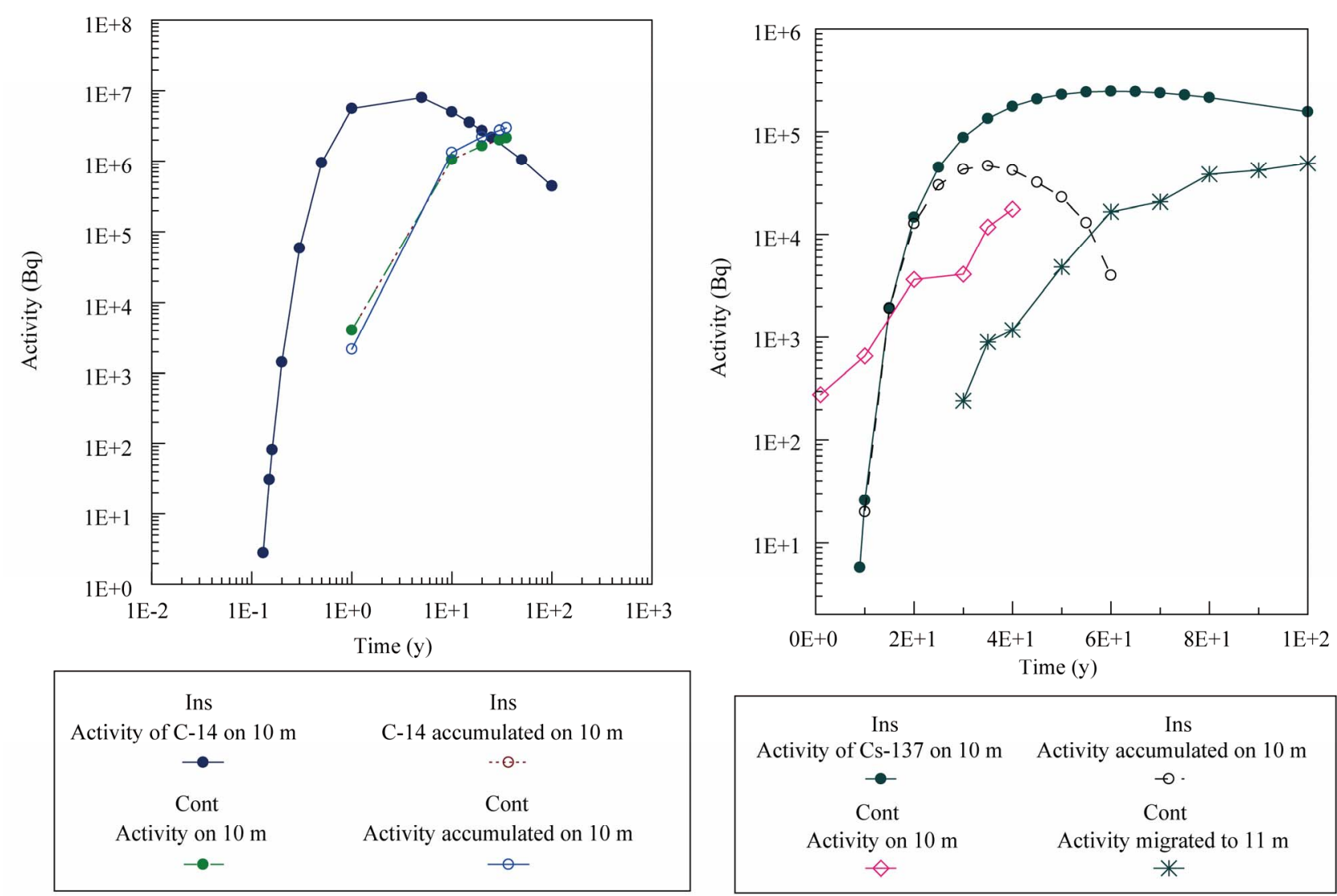

\begin{tabular}{|c|c|}
\hline $\begin{array}{c}\text { Ins } \\
\text { Activity of Cs-137 on } 10 \mathrm{~m}\end{array}$ & $\begin{array}{c}\text { Ins } \\
\text { Activity accumulated on } 10 \mathrm{~m} \\
\bigcirc .\end{array}$ \\
\hline $\begin{array}{c}\text { Cont } \\
\text { Activity on } 10 \mathrm{~m} \\
\qquad\end{array}$ & $\begin{array}{c}\text { Cont } \\
\text { Activity migrated to } 11 \mathrm{~m} \\
*\end{array}$ \\
\hline
\end{tabular}

Figure 6. Comparison of the modes instantaneous and continuous modes.

- The pollution of the area should be monitoring to not exceed the restricted area around the disposal site.

- The study should be within a reasonable enough period of time for performing good results.

- Detail analysis of different parameters and factors affect the rate of release from the disposal site should be considered.

- Possible pollution should be evaluated considering different factors

- The mode of release is from the important should be undertaken in this chapter.

- The instantaneous mode can pollute a long distance 
but with low activity.

- The continuous mode pollutes a restricted area within high concentration.

- The appearance of each radionuclide should be monitored at selected distance within the restricted area around the burial area.

- Some radionuclide moves very quickly but does not require any remediation because it does not reflect a real pollution case. Some radionuclide moves very slowly enough to detect and to perform suitable remediation techniques.

- Decontaminations and remediation plans should be demonstrated in this chapter for assessment by regulatory bodies.

\section{References}

[1] International Atomic Energy Agency, "Preparation of Safety Analysis Reports (SARs) for Near Surface Radioactive Waste Disposal Facilities," IAEA, Vienna, TECDOC-No 789, 1995.

[2] International Atomic Energy Agency, "Derivation of Activity Limits for the Disposal of Radioactive Waste in Near Surface Disposal Facilities," IAEA-TECDOC-1380, December 2003.

[3] H. K. Jean and B. J. Broomfield, "Scope of Work for the Operable Unit 7-13/14 Waste Area Group 7 Comprehensive Remedial Investigation/Feasibility Study, INEL-95/ 0253," 2nd Revision, Idaho National Engineering and Environmental Laboratory, Idaho, 2003.

[4] M. Munakata, H. Kimura and H. Matsuzuru, JAERI-Research, "Source Term and Analysis for Vault/Trench Facilities Located in an Unsaturated Zone," Japan Atomic Energy Research Institute, Masaji Yoshikawa, June 1995.

[5] N. S. Mahmoud and S. El Hemamy, "On the Possible Leakage of ET-RR1 Liquid Waste Tank; Hydrological and Migration Modes Studies," Scientific World Journal, Vol. 5, 2005, pp. 234-252. doi:10.1100/tsw.2005.34

[6] International Commission on Radiological Protection, "Limits for Intakes of Radionuclides by Workers," Annals of the ICRP, Pergamon Press, Oxford, Vol. 30, 1979-1983.
[7] P. A. Domenico and G. A. Robbins, "A New Method of Contaminant Plume Analysis," Groundwater, Vol. 23, No. 4, 1985, pp. 476-485. doi:10.1111/j.1745-6584.1985.tb01497.x

[8] P. A. Domenico and F. W. Schwartz, "Physical and Chemical Hydrology," Text Book, John Willey \& Sons, Hoboken, Copyright 1990.

[9] J. E. Till and H. R. Meyer, "Radiological Assessment," $A$ Text book on Environmental Dose Analysis, GPO Sales Program, Nuclear Regulatory Commission, Washington DC, 1983. doi:10.2172/5407895

[10] Office of Environmental Restoration, "Decision-Making Framework Guide for the Evaluation and Selection of Monitored Natural Attenuation Remedies at Department of Energy Sites," Office of Environmental Management, US Department of Energy, Washington DC, 13 May, 1999.

[11] Office of Environmental Restoration, "Technical Guidance for the Long-Term Monitoring of Natural Attenuation Remedies at Department of Energy Sites," Office of Environmental Management, US Department of Energy, Washington DC, 8 October, 1999.

[12] M. McCormack, "Phytoremediation," December 3, 2000

[13] http://fbox.vt.edu/users/mmccorma/webpage.htm

[14] B. E. Pivetz, "Phytoremediation of Contaminated Soil and Ground Water at Hazardous Waste Sites," EPA, United States Environmental Protection Agency, Ground Water Issue, Washington DC, EPA/540/S-01/500, February 2001 .

[15] National Research Council, "Groundwater \& Soil Cleanup, Improving Management of Persistent Contaminants," Committee on Technologies for Cleanup of Subsurface Contaminants in the DOE Weapons Complex, National Academy Press, Washington DC, 1999.

[16] M. Rahbeh, "Evaluating the Capture Zones of the Pump-Treat Remediation Technique," Agricultural and Biological Engineering Department, Purdue University, West Lafayette, December 15, 1999.

[17] J. F. Zitnik, A. T. Armstrong, B. K. Corb, M. H. Edens, D. B. Holsten, P. M. O'Flaherty, J. Rodriguez, T. N. Thomas, R. L. Treat, W. Schofield and K. L. Sykes, "Preliminary Evaluation of Remedial Alternatives for the Subsurface Disposal Area," INEEL/EXT-02-01258, Prepared by CH2MHILL for the Idaho National Engineering and Environmental Laboratory, Idaho, December 2002. 